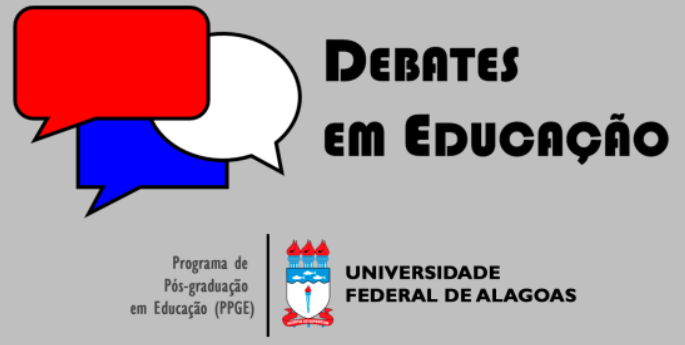

ISSN Eletrônico 2175-6600

Vol. 12 | N. 28 | Set./Dez. | 2020

Elaine Teresinha Dal Mas Dias

9 iD

Universidade Nove de Julho (UNINOVE) etdmdias@gmail.com

\section{ALUNOS COM NECESSIDADES EDUCACIONAIS ESPECIAIS NO ENSINO REGULAR: OBSTÁCULOS E LIMITES}

\section{RESUMO}

Este artigo é um recorte dos resultados da pesquisa de campo realizada por Takase. Objetiva, em abordagem qualitativa subsidiada pelo pensamento complexo, releitura das entrevistas com professoras, identificando os processos inclusivos, as experiências pessoais e a compreensão das necessidades educacionais especiais dos alunos e analisar as subjetividades, articulando-as às práticas e processos socioculturais. Conclui que objetividade e subjetividade são tecidas simultaneamente e manifestas na realidade, na germinação da insatisfação que fere o psiquismo e adoece, interferindo no ato pedagógico e na aprendizagem; que profecias autorrealizadoras podem atingir o alunado NEE, reforçando preconceitos e exclusão e que sentimentos de desamparo e de frustração estão presente no cotidiano.

Palavras-chave: Formação docente. Trabalho Docente. Educação Inclusiva.

\section{STUDENTS WITH SPECIAL EDUCATIONAL NEEDS IN REGULAR EDUCATION: OBSTACLES AND LIMITS}

\begin{abstract}
This article is an excerpt from the results of the field research carried out by Takase. It aims, in a qualitative approach subsidized by complex thinking, re-reading interviews with teachers, identifying inclusive processes, personal experiences and understanding the students' special educational needs; and analyzing subjectivities, articulating them with sociocultural practices and processes. It concludes that objectivity and subjectivity are woven simultaneously and manifest in reality, in the germination of dissatisfaction that hurts the psyche and gets sick, interfering in the pedagogical act and in the learning; that self-fulfilling prophecies can reach SEN students, reinforcing prejudices and exclusion; and that feelings of helplessness and frustration are present in everyday life.
\end{abstract}

Keywords: Teacher education. Teaching work. Inclusive education.

Submetido em: 28/06/2020

Aceito em: 08/07/2020

Publicado em: 18/08/2020

do http://dx.doi.org// 0.28998/2 I 75-6600.2020v I 2n28p65 I-664 


\section{INTRODUÇÃO}

O nosso conhecimento do homem não elucidou o inconsciente humano, mas abre, apenas, os múltiplos abismos desse inconsciente. E. Morin (2002, p. I2I)

Este trabalho estuda e analisa o conjunto de entrevistas estruturadas da pesquisa de campo realizada por Daniele Takase ${ }^{1}$, em 20l I. Os objetivos específicos do estudo consistiram em identificar como professores situavam-se em relação à inclusão de alunos com necessidade educacionais especiais (NEE), às dificuldades encontradas em sua atuação pedagógica e à busca pela formação continuada na perspectiva inclusiva. A hipótese orientadora da investigação supõe que a formação continuada dos professores promove uma educação inclusiva.

As docentes colaboradoras, um grupo exclusivamente feminino, em número de 13 e idade média de 44 anos, pertenciam a duas instituições de ensino da rede pública estadual paulista, localizadas nas regiões Norte e Centro-Oeste do município de São Paulo. A formação acadêmica era variada, predominando as ciências humanas, em particular, as ciências pedagógicas. É possível afirmar que o grupo detinha ampla experiência profissional, pois apenas seis docentes exercem a função há menos de oito anos.

Quadro I identifica e caracteriza as professoras cujas respostas serão analisadas sob outra perspectiva teórica, como se verá adiante.

\begin{tabular}{|c|c|c|c|c|}
\hline Professora & Sexo & Idade & Tempo de Serviço & Formação \\
\hline I & F & 31 & 14 & Magistério/Pedagogia \\
\hline 2 & F & 32 & 8 & Pedagogia/especialista Psicopedagogia \\
\hline 3 & F & 45 & 4 & Pedagogia/Psicologia \\
\hline 4 & F & 55 & 18 & Ciências Jurídicas \\
\hline 5 & F & 50 & 31 & Magistério \\
\hline 6 & F & 44 & 18 & Magistério/Pedagogia \\
\hline 7 & F & 47 & 3 & Pedagogia \\
\hline 8 & F & 41 & 22 & Pedagogia \\
\hline 9 & F & 46 & 25 & Magistério/Pedagogia \\
\hline I0 & F & 59 & 20 & Pedagogia/especialista em Pré-Escola \\
\hline II & F & 48 & 32 & Pedagogia \\
\hline I2 & F & 35 & 7 & Pedagogia \\
\hline I3 & F & 56 & 18 & Pedagogia/Filosofia/especialista/ Supervisão escolar \\
\hline
\end{tabular}

Fonte: Daniele G. A. Takase (201 I).

As escolas participantes funcionam nos turnos matutino e vespertino. A primeira $(A)$ atendia, à época do estudo, um global de 566 alunos distribuídos em: quatro turmas de primeira série, totalizando

\footnotetext{
I Trabalho completo disponível em: http://capesdw.capes.gov.br/Fcapesdw/resumo.html?idtese =20 | | 5330920 I0002P2
} 
II 6 crianças; quatro de segundas séries com I19; seis turmas de terceira séries com 164; seis de quartas séries com 167; e duas salas de Recursos com 31 alunos com dois docentes especialistas.

A segunda (B), com 465 matriculados organizados em quatro turmas para cada uma das séries, integrando I 20 crianças nas primeiras, I I3 nas segundas, I I I nas terceiras, I 2 I nas quartas e uma sala de educação especial, com 16 alunos matriculados e uma sala de recursos, contando 22 alunos e cada turma, tem uma professora especialista.

Takase $(201$ I ) ressalta que nas escolas do estado de São Paulo existem dois modos de atendimento aos alunos com NEE: a sala de recursos e as classes especiais. Ambos são amparados pela Lei de Diretrizes e Bases, de 1996 (LDB/96), e pela Deliberação do Conselho Estadual de Educação (CEE) n 5/2000, visando à inclusão. Os atos legais dispõem que é delegada às unidades escolares:

a) a identificação dos alunos que necessitam de atendimento especial;

b) o estabelecimento de estratégias de recuperação para alunos com menor rendimento escolar;

c) a articulação entre família e comunidade;

d) a adaptação dos currículos;

e) a adequação de metodologias de ensino;

f) e a seleção de recursos educativos com vistas à problemática dos alunos (BRASIL, 1996; SÃO PAULO, 2000).

Diante desse panorama e dada a significância das respostas obtidas pela autora, propõe-se, em primeiro lugar, efetuar um recorte enfocando as que dizem respeito à inclusão, às experiências e à compreensão das docentes quanto ao tema; em segundo, analisá-las e discuti-las visando às possíveis particularidades e/ou os aspectos das subjetividades, articulando-os aos encargos, às práticas diárias e aos processos socioculturais. O pensamento complexo na elaboração de Edgar Morin (1975, 2002, 2004a, 2004b, 2005a, 2005b) subsidiará esta incursão.

\section{PERSPECTIVA TEÓRICA: PENSAMENTO COMPLEXO}

O pensamento complexo se distingue do pensamento tradicional clássico por não impor segmentações ou disjunções, por não fornecer elucidações de antemão e por não restringir suas formulações a ideias únicas e simplificadas. Parte, segundo Morin (2005, p. 7), da ousada proposta de ansiar por um conhecimento multidimensional, sem almejar completudes ou certezas "[...] animado por uma tensão permanente entre a aspiração a um saber não fragmentado, não compartimentado, não redutor, e o conhecimento do inacabado e da incompletude de qualquer conhecimento.". 
Essa formulação se caracteriza pela inseparabilidade entre uno e múltiplo, subjetividade e objetividade, singularidade e diversidade, poético e prosaico, ciência e cultura. Isto significa dizer que a complexidade se constitui na conjunção de heterogeneidades, na desordem, na ambiguidade e nas incertezas. A proposição da complexidade é a de sensibilizar, por um lado, para as falhas e lacunas do pensamento simplificador e, por outro, para que essas mesmas falhas e lacunas conduzem a ações mutiladoras.

Morin (2005a) postula que a vida do homem e do mundo foi descrita com maestria nos romances do século XIX, em que foram expostos seres reais contextualizados em um tempo e uma época, cuja cotidianidade estava onde são jogados e combinados os inúmeros papéis sociais. Nos espaços e lugares desenhados nessas histórias presentificavam-se e escamoteavam-se, simultaneamente, múltiplas personalidades em um mundo de fantasias que preenchiam experiências e vivências.

Em contraposição, no mesmo período novecentista, as ciências impuseram uma concepção determinista e perfeita de universo que passou a eliminar a desordem, a imprevisibilidade e a singularidade, distanciando-se do sensível, da ficção, da mitologia. A cristalização das imposições se mantém ancorada na visão de homem cindindo entre o biológico e o cultural; o racional e o irracional; o sujeito e o objeto, que presa as elaborações, exclusivamente, técnico-científicas. Entretanto, como assinala Morin (2005b, p. 65, grifo do autor):

[...] hoje não apenas a física põe num cosmos singular, mas as ciências biológicas nos dizem que a espécie não é um quadro geral no qual nascem indivíduos singulares, a espécie é, ela própria, um padrão singular muito preciso, um produtor de singularidades. Além disso, os indivíduos de uma mesma espécie são muito diferentes uns dos outros. Mas deve-se compreender que há alguma coisa além da singularidade ou que a diferença de um indivíduo a um outro está no fato de que cada indivíduo é um sujeito.

Ser sujeito não denota ser somente consciente, pois segundo o autor (2004b, pp. 85-86), "existe a impossibilidade de ser totalmente consciente do que se passa na maquinaria de nossa mente, que conserva sempre algo de fundamentalmente inconsciente". Expressa o preenchimento do lugar do "eu" egocêntrico, situado no âmago do próprio mundo que se articula aos princípios da exclusão - que é a unicidade de cada um -, e o da inclusão - a aceitação subjetiva de pessoas ou fenômenos da realidade que tocam afetivamente. Para Morin (idem, p. 52), soma-se ainda, o fato de ser "a um só tempo plenamente biológico e plenamente cultural, que traz a unidualidade originária." Autônomo-dependente, transitório, hesitante.

Vale reforçar que essas características têm ligação estreita e direta com as condições socioculturais e são nutridas pela dependência da educação, da linguagem, da literatura, dos genes, das células-tronco, sinalizando a provisoriedade da autonomia.

Em consonância com Morin (2004b, p. 56), entende-se cultura como: 
[...] um conjunto dos saberes, fazeres, regras, normas, proibições, estratégias, crenças, idéias, valores, mitos, que se transmite de geração em geração, se reproduz em cada indivíduo, controla a existência da sociedade e mantém a complexidade psicológica e social.

Tal reprodução marca o indivíduo desde o nascimento como um 655 mprintings $^{2}$ que, para o referido autor (2005b, p.302), "inscreve-se cerebralmente na primeira infância pela estabilização seletiva das sinapses, inscrições primeiras que vão marcar irreversivelmente o espírito individual no seu modo de conhecer e de agir," refletindo, de início, o selo da família e depois da escola, das instituições que passa a comungar, dos parceiros. A cultura, para Morin (2005b, p. I66),

[...] pela influência precoce, pelas interdições, pelos imperativos, pelo sistema de educação, pelo regime alimentar, pelos modelos de comportamento, recalca, inibe, favorece, estimula, determina a expressão das aptidões individuais, exerce seus efeitos sobre o funcionamento cerebral e sobre a formação do espírito, interferindo para co-organizar, controlar e civilizar o conjunto da personalidade. Assim a cultura submete o indivíduo e, ao mesmo tempo, o autonomiza.

A união desses fatores constitui a subjetividade, conceituada como um sistema que provoca organizações e desorganizações no mundo interno e no externo do sujeito, interdita e propicia o desenvolvimento e o crescimento pessoal, comporta a afetividade e coloca o passado, tangenciando o agora do presente e atraindo o futuro, e fazendo-se por intermédio da intersubjetividade (DIAS, 2008).

A intersubjetividade se estabelece na ininterrupta troca de significados entre sujeitos no compartilhamento do dia-a-dia que, acumulados e selecionados, são transmitidos conformando indivíduos, delineando identidades e produzindo tipos específicos de personalidades. Essas especificidades decorrem do fato de que cada ser é único, incompleto e sem similar entre os seus antecedentes e descendentes, apesar das semelhanças e igualdades da espécie e da complementação que ocorre a cada dia, na composição de histórias de vida inusitadas e partilhadas, estabelecendo os contornos do homo complexus.

A abertura ao sujeito acontece, quando se reconhece no outro os mesmos mecanismos que movem ou paralisam a humanidade. Para Morin (2004ª , p.5 I), "é a partir da compreensão que se pode lutar contra o ódio e a exclusão" e, com auxílio da ecologia da ação, subverter a (com)formação como estratégia.

Regida por dois princípios, a ecologia da ação considera, conforme o autor (2005b, p. 30 I), que "a ação não depende apenas das intenções do ator, mas também das condições próprias ao meio onde se desenvolve; [e que] os efeitos a longo tempo da ação são imprevisíveis.".

Assim, subjetividade, intersubjetividade e ecologia da ação são componentes de um mesmo processo complexo - dialógico, recursivo e hologramático -, que imbrica e influencia, complementa e antagoniza contínua e concomitantemente o todo que está na parte, que está no todo. Pensar a

\footnotetext{
2 Termos em itálico correspondem aos empregados por E. Morin em suas obras e em língua estrangeira.
} 
subjetividade imune à ecologia e livre da intersubjetividade é isolar e reduzir a fragmentos o que é complexus, o que é tecido junto; é colocar os seres humanos como meras máquinas triviais das quais se projetam e esperam comportamentos padronizados.

Ao se dedicar a pensar a cultura e ao 656 mprintings, ressalva-se que Morin (2002, p. 33) não está referindo-se aos indivíduos deficientes ou aos alunos com NEE especificamente; na verdade, está preocupado com os "pontos de vista cognitivamente muito variados" que são inibidos e reprimidos. Empresta-se aqui esse pensamento para uma reflexão sobre as diferenças na espécie humana que provoca silenciamentos equivalentes. Para o autor, há uma crise dos fundamentos éticos que exacerba a deterioração do tecido social, atenua o imperativo comunitário, suaviza as responsabilidades, inflaciona o egocentrismo em detrimento do altruísmo e desarticula a vinculação entre individuo-espécie-sociedade. Diz Morin (2005c, p. 29, itálico no original): "Vale repetir: o ato moral é um ato de religação: com o outro, com uma comunidade, com uma sociedade e, no limite, religação com a espécie humana".

Sob esse prisma, é fundamental uma reforma do pensamento em que a conjunção é uma das palavras mestras e com a qual se conjuga também a compreensão humana que, para o referido autor (idem, p. I I 5), "comporta não somente a compreensão da complexidade do ser humano, mas também a compreensão das condições que são forjadas as mentalidades e praticadas as ações," que desembocam na compreensão complexa, articuladora da compreensão objetiva e da compreensão subjetiva em seus aspectos singulares e globais e na integração de polaridades situacionais e distintas de um mesmo fenômeno (MORIN, 2005c). Esses desdobramentos envolvem processos psicológicos básicos como pensamento, linguagem, memória, percepção, e abarcam os complexos imaginários formados pela tríade projeção, identificação e transferência e nomeadas PIT.

As emoções expressas pelas PIT fixam-se no exterior na figura de alguém, de um objeto ou de um mito como transferência e externalização de estados subjetivos geradores de identificações, evidenciando o homo sapiens/demens.

Indivíduo/sujeito e sociedade/cultura estão unidos por tramas interdependentes que predispõem as pessoas a ações similares e à exposição de saberes que replicam conceitos e preconceitos. É oportuno salientar a importância de uma conservação vigilante à segregação, porque reúne traços objetivos e subjetivos, cabendo à educação, conforme Morin (2004b, p.55), "cuidar para que a idéia de unidade da espécie humana não apague a idéia de diversidade e que a da sua diversidade não apague a da unidade".

Com base nessas ideias levantam-se outras leituras sobre como os docentes pensam e como compreendem a inclusão, a partir dos mesmos discursos, como se verá a seguir. 


\section{OUTROS OLHARES}

O ponto de partida são as respostas às perguntas elaboradas por Takase (20 I I) particularizadas pela inclusão de alunos com NEE como anunciado, que serão transcritas por completo, quando favorecerem a análise e seu entendimento ou se restringirem às expressões significativas (ES), designação dada a algumas frases dos discursos por apresentarem um significado implícito e passível de interpretação (DIAS, 1997). As narrativas das professoras colaboradoras da escola A serão as utilizadas neste momento. Inicia-se com a questão número I0: Diz Takase (20 I I, p. I I I): "atualmente há uma discussão na sociedade sobre a inclusão do aluno com necessidades educacionais especiais na escola de ensino regular. Qual é a sua visão sobre essa discussão?" .

\footnotetext{
- |a: "Infelizmente a questão da inclusão parece muito bonita, mas na realidade não é. $O$ aluno é "incluso" em sala de aula, porém apenas socialmente.".

- 6a: "O aluno está incluso socialmente, mas os recursos são pouquíssimos; é complicado para o professor dar uma atenção específica para esse aluno já que não teve preparo para lidar com os mesmos e as salas são numerosas."

- 7a: "O discurso é comovente. A prática ainda está sendo uma utopia."

- 8a: "O professor se vê perdido e sozinho."

- 10a: "Ainda há muito a ser feito para que os alunos com necessidades especiais sejam inclú́dos na sala regular."
}

Sem a pretensão de julgamento e procurando compreender o discurso das docentes, nota-se certa tensão entre o vivido e o realizável, entre o objetivo e o subjetivo. Quer dizer, no concreto, a legislação e a sociedade fixam obrigações educacionais aos portadores de NEE que devem se acatadas e efetivadas, não obstante os entraves para que sejam cumpridas, como a quantidade de alunos em sala e a individualização do ensino. Contudo, o emprego dos elementos lexicais, "infelizmente", "incluso" e "utopia", dão a versão da situação em que se encontram os alunos e adicionam uma crítica severa à imposição e à qualidade da formação, deixando dúvidas quanto à incorporação dos preceitos. Os argumentos se justificam e parecem revelar sentimentos de desamparo e de frustração frente às situações e à obrigatoriedade do cumprimento legal. Não é possível se afirmar a discriminação, mas a dureza das descrições sugere bloqueios à aceitação da diferença em sala, particularmente, segundo Takase (20 I I, p. |3|), quando sarcasticamente se diz: "O discurso é comovente.".

Em direção aproximada, a professora $2^{a}$ proclama como sente e vive a inclusão do aluno com NEE. Está isolada das demais por sua clareza e denúncia: "Acho complicado. É uma inclusão feita pela metade: o aluno vai, mas as condições não mudam. [...]- basear a inclusão no bom senso do professor é um atentado - falta profissionalismo, falta formação." (TAKASE, 20। I).

Esta descrição é contundente e incisiva, pois aborda o valor das políticas públicas imperativas que se configuram paliativas e, nem sempre, funcionam em decorrência de acontecimentos escolares; do número de alunos por turma; da falta de formação específica do professor para o desempenho da função; 
da cautela em publicizar sua apreensão do sistema, devido ao desgaste que pode provocar junto aos demais colegas, entre outras. Objetividade e subjetividade estão tecidas ao mesmo tempo e manifestas na concretude do dia a dia, na germinação da insatisfação e do descontentamento que pode ferir o psiquismo e provocar adoecimentos que interferem no ato pedagógico e na aprendizagem dos alunos, independente de suas condições (DIAS, 2010)

Foram identificados também alguns condicionantes para a inclusão, como por exemplo.

- 3a: "Acredito que a inclusão do aluno com NEE é necessária, desde que este aluno apresente condições para estar com os outros alunos." (TAKASE, 201 I, p. 130).

- 5a: "Funcionaria muito melhor se fosse feito de forma diferente: incluir alunos que dominassem algum conteúdo comum." (id, p. 130).

A condicional sugerida pelas docentes fere a legislação, especializa a caracterização do portador de NEE e colore, com tons intensos, prováveis discriminações e preconceitos latentes que não devem vir à luz. Há, nessas respostas, certo grau de rejeição e de sentimentos velados dirigidos ao aluno, prejudiciais ao desenvolvimento cognitivo e social que merecem revisão dos afetos e outra atenção pedagógica. A insatisfação das educadoras é transparente, pois recomenda o domínio de algum conteúdo sem relacionálo às especificidades de cada criança que diferem substancialmente haja vista os casos de deficiências, transtornos e síndromes. Apropriações das NEE como estas são excludentes, disfarçam a exclusão e desaconselham o recebimento de qualquer um que revele algum vazio na aprendizagem.

O preconceito foi declarado nos depoimentos a seguir.

- 4a: "Ainda vivemos numa sociedade arcaica, onde ainda está longe de alcançar a verdadeira inclusão, pois vivemos numa sociedade cheia de preconceitos e discriminação."

- 9a: "A sociedade ainda é preconceituosa e discriminatória."

Essas professoras iluminam as considerações das anteriores $3^{\mathrm{a}}$ e $5^{\mathrm{a}}$. $\bigcirc$ preconceito existe porque a sociedade, mesmo que implicitamente, adverte e conspira contra os que não seguem as normas ou as pretensas normalizações (CROCHIK, 1997), que são repressivas, intimidadoras e sufocantes.

Ser diferente bloqueia a chance de pertencimento e delata a pseudo-superioridade daquele que é igual. $\bigcirc$ afastamento une o grupo pela ausência da diferença e pela extradição do estrangeiro que é outro, diferente ou não, prevalecendo a linearidade do pensamento que sanciona práticas sociais estigmatizantes, perpetuando os processos culturais que reproduzem as estereotipias. Cenas escolares segregadoras são validadas pela comunidade científica tradicional, ao oferecer bases de sustentação à reificação de comportamentos que, em muitas ocasiões, são manifestações episódicas que, contudo, marcarão as pessoas fortemente.

A pergunta seguinte utilizada é a de número 12 "Você já presenciou algum tipo de preconceito ou exclusão em relação a esses alunos?" É importante validar que embora se refira ao preconceito umas 
respostas anteciparam-no evidenciando a presença desse sentimento-comportamento mais do que se admite.

|a: "Não, nossa escola possui uma postura inclusiva, atende carinhosamente e da melhor maneira possível.".

A resposta da professora $I^{a}$ fortifica a suspeita de frustração na qualificação do processo educacional inclusivo como carinhoso e fazendo-se da melhor maneira possível, pois expõe um hiato entre a efetividade da ação e o atendimento oferecido, proveniente talvez de ambíguos sentimentos de resignação, principalmente porque a pergunta é pontual, e de desamparo que advém da falta de conhecimento e de abrigo técnico para um ensino consistente, a depender das condições dos alunos e da responsabilização pelo ato educativo.

- 4a: "Presenciei sim, fiquei muito decepcionada e ao mesmo tempo me senti com as mãos atadas sem poder fazer muita coisa ou quase nada. Ainda existe preconceito e discriminação por parte de certos alunos."

- 7a: "Sim."

- 8a: "Já presenciei preconceito."

- 12a: "Sim, infelizmente."

A crença na extinção do preconceito é irreal. A sociedade e a cultura repercutem a discriminação que, como sentencia Morin (2004b), se reproduz em cada pessoa e controla a sociedade. Educação e compreensão complexa são forças que podem liberar a sociedade, a cultura e o homem de suas raízes primitivas que exigem o extermínio do desigual, do díspar. Entretanto, ao se recordar de atrocidades recentes e passadas cometidas por insanos de toda ordem, verifica-se que se está muito longe de alcançar essa evolução.

A próxima é a questão 13. Takase (2011, p. 135): "quando um aluno é diagnosticado com necessidades educacionais especiais?"

- I’: "Quando começamos a perceber alguma dificuldade no aluno, encaminhamos para uma avaliação pediátrica."

- 2a: "Quando o aluno é encaminhado para um especialista."

- 3a: "O aluno já é encaminhado para a classe, às vezes com um laudo, às vezes a própria coordenadora avisa que o aluno tem necessidades especiais."

- 4a: "O professor consegue detectar algum problema com a ajuda do especialista habilitado ou com laudo médico."

- 5a: "São alunos que apresentam comprometimento no desenvolvimento cognitivo, atrapalhando a sua aprendizagem convencional."

- 6a: "Através de laudos médicos."

- 7a: "Quando apresenta significativa diferença física, sensorial e intelectual, decorrente de fatores inatos ou adquiridos, de caráter permanente ou temporário que acarretam dificuldades em sua interação com o meio."

- 8a: "Normalmente, ele já vem da sala especial com laudo e é incluso."

- 9a: "O professor consegue detectar algum problema, porém o educando precisa de uma avaliação de um especialista."

- 10a: "O professor encaminha para o especialista em educação especial fazer uma avaliação."

- 13a: "Não sou especialista no assunto.". 
A interpelação suscitou divagações convergindo para os tortuosos percursos enfrentados pelas crianças com NEE e por seus familiares, o reducionismo e a dispersão dos procedimentos, distanciamento da temática, ostentação de posturas impróprias e descolamento da responsabilidade socioeducativa. Somente as docentes $5^{a}, 7^{a}$ e $9^{a}$ explicam quando o aluno é diagnosticado, as demais se distanciam ou indicam quem o determina. A pouca informação, a incompreensão, o temor de uma classificação equivocada, a falta de implicação ou ainda o descaso para com a pesquisa, especialmente pela crueza ou objetividade das exposições como em 13a , por exemplo, podem estar na raiz dessas reações.

É interessante registrar os vínculos entre o desconhecimento e os cursos de formação de professores. Estes, em geral, contemplam parcialmente o estudo das deficiências e das condutas típicas e traçam um panorama das causas, prevalências e consequências das malformações e das doenças, competindo ao interessado o aprofundamento e a formação continuada que conferiria saberes. Os efeitos disso são identificações fraturadas do portador de NEE centradas em apreensões objetivas que eliminam o sujeito e transpiram afetos dissimulados, tornando-o um evento. Considera-se fundamental, como explica Morin (2005c), que sejam retomadas as condições nas quais são forjadas as mentalidades e praticadas as ações, sem esquecer da imprevisibilidade das ações ao longo do tempo.

Diante do quadro, compete um alerta quanto aos encaminhamentos. Vários autores (MOYSÉS; COLLARES, 1996; SOUZA, 2003; PATTO, 1993; DIAS, 20I2; CARONI, 20I I; MOCELIN, 20I4) têm se dedicado a estudar os efeitos devastadores de tais indicações, que desviam a atenção do educador para as dificuldades do aluno e para a profetização do fracasso escolar, individualizando-o pelos impedimentos que eliminam o sujeito da relação professor/aluno, colando-o na posição de objeto defeituoso. As expressões "aluno de inclusão" e "quando tem um laudo" são pistas da situação em que se encontra o alunado.

O trabalho de Moysés e Collares (1997) espelha essa conjuntura ao selecionar os encaminhamentos aos serviços de saúde e educacionais que tendem à manutenção de um ideário eugenista que emudece o sujeito, à evitação de uma busca por pessoas concretas e à procura de um potencial de inteligência que não será encontrado.

Embora os instrumentos de avaliação psicológica tenham evoluído e sofrido substanciais alterações nas últimas décadas, tanto quanto às validações como nas verificações, é fácil encontrar uma parcela expressiva de profissionais que não atendem a esse chamamento e continuam a avaliar crianças nos modelos tradicionalistas dos anos 1970-80, puramente quantitativo. Algo semelhante acontece nas indicações aos médicos e aos psicopedagogos, como também distinguem as autoras, que incorrem em problemas análogos no ajuizamento dos pacientes e na aplicação e correção dos materiais avaliativos empregados. 
Nota-se, nas respostas, a constância dos elementos que operam a complexidade, em que o todo está na parte que está no todo, em uma dinâmica reprodutiva permanente, antagônica e complementar: a escola e a educação estão nos professores e alunos que fazem a escola e educação e vice-versa, em posições inconfundíveis, porém complementárias. Todavia, esses elementos não são assim percebidos, porque pautados em relações excludentes e segmentadas: professores de um lado e alunos de outros.

Na questão |4, Takase (20 I I. P. I 36): "você tem alguma dificuldade no trabalho com esse aluno? Exemplifique", a variedade de percepções do fazer educacional é peculiar, embora se assemelhem na desqualificação, no deslocamento dos problemas, na projeção, na discriminação e nas ambivalências que atravessam o ato educativo e a subjetividade docente. Em 10 a a discriminação antecede o acolhimento que é resgatado por culpa ou penalização da condição do aluno: "com esse tipo de aluno é preciso muita atenção, carinho e dedicação individual e é assim que trabalho com alunos especiais"; $3^{\mathrm{a}}$ e $6^{\mathrm{a}}$ centram-se nas mesmas teses e nos limites visíveis da situação individual e I l a acrescenta a precisão de uma avaliação valorativa.

- 3a: "Com meu aluno em particular eu não tenho dificuldade, porque já sei até onde ele pode chegar e não cobro dele mais do que ele pode, então fica tudo bem."

- 6a: "Não tenho dificuldade. Ele convive dentro de suas limitações normalmente, afinal, todos nós temos limitações."

- I la: "Sim. Até hoje não sei o grau de deficiência da minha aluna.".

Outras professoras focalizam a falta de especialização para um atendimento adequado ao aluno, como já descrito e associado a perguntas diferentes.

- 4a: "Creio que para todas as pessoas ou profissionais que não têm habilitação para a área ou especialização, fica mais difícil."

- 9a: "Depende do grau de dificuldade, pois existem necessidades que o educando precisa do especialista da área propícia."

- 12 A: "Faltam materiais e orientação para um melhor trabalho com esse aluno."

assunto formação é recorrente à profissionalização e foi amplamente abordado por Takase (201 I) inclusive em perguntas dirigidas, como a 16a. "Você se considera preparado para lidar com esse aluno?". Apenas as professoras $7^{\mathrm{a}}$ e $10^{\mathrm{a}}$ consideram-se preparadas.

A formação e a inclusão como obrigatoriedade comparecem como fatores predominantes quando se margeiam os motivos pelos quais a incumbência do aluno que apresenta NEE é tão problemática. Raras foram as docentes que se inseriram como co-responsáveis pelo crescimento ou não do aluno, como se verifica em I a ao mirar seus ajuizamentos em seu desempenho: "Acredito que falho, pois não consigo oferecer a eles toda a atenção necessária", percebendo os embaraços que the são impostos pelo tempo, pela quantidade de alunos em classe, pela formação. Esta percepção permeada de sentimentos e emoções dá a conhecer uma educadora preparada para olhar-se e absorver as circunstâncias externas sem negar a 
própria participação. A maioria pautou-se em profecias autorrealizadoras que podem atingir e sitiar sobremaneira o portador de NEE reforçando os quadros preconceituosos (PATTO, 1993, 2005).

Os pronunciamentos à pergunta 15 - Como é a aceitação da comunidade escolar com relação à inclusão desses alunos nas salas regulares? -, são interessantes, pois anteriormente, as docentes indicaram a presença do preconceito e nesta, exclusivamente, duas afirmam sua ocorrência sem descartarem a real existência do sentimento nas famílias.

- Ia: "Já presenciei episódios de exclusão por parte dos pais".

- 4a: "Ainda existe preconceito por parte de alguns pais.".

Houve um pronunciamento, segundo Takase (201 I, p. 139), que vai ao encontro dos dizeres de Morin $\left(2004^{a}\right)$ no que se refere ao ódio, à exclusão e à compreensão: "I Ia: Os pais aceitam, pois é explicado na primeira reunião quando há alguma inclusão". Essa informação é preciosa, porque abre caminhos aos meios resistentes que obstruem o pertencimento e destroem o poder de reversão que muitos alunos têm. Todavia, seria ingênuo pensar que a mera explicação é suficiente; a compreensão ultrapassa a explicação e comporta um saber de sujeito a sujeito que identifica e transfere afetos e emoções favorecedoras ou não de mudanças.

\section{ARREMATANDO A TESSITURA}

A pista para a alteração dessas disposições socioculturais e individuais está na reforma do pensamento. Esta pede um pensar apto a abarcar os conjuntos e dilatar o senso de responsabilidade e de cidadania, tratando os saberes das partes como dependentes dos saberes do todo que dependem dos saberes das partes, com um olhar voltado às multidimensionalidades da vida e dos seres com respeito às diferenças e reconhecimento da unidade.

Nesse encadeamento, a abertura subjetiva em relação ao outro demanda uma ética compreensiva e desinteressada que apreende os requisitos que regem os comportamentos, as atitudes e os estados humanos. Os educadores, nessa dinâmica, seriam os mandatários de um trabalho ininterrupto de humanização - própria e do outro - em que objetividade e subjetividade seriam persistentemente avaliadas e ressignificadas.

Abrigar as discrepâncias sociais, culturais ou biológicas exige uma persistente vigilância dos atos e ações que escorregam, fogem do controle, e obstruem a liberdade do espírito para compreensão, identificação e incorporação do outro em mim. Tarefa exigente que impõe ao professor atenção ao alargamento do individualismo narcísico que tolhe e reduz, mas que, ao ser atingido, talha no horizonte um novo fazer, uma nova práxis. 


\section{REFERÊNCIAS}

BRASIL. Lei n 9.394, de 20 de dezembro de 1996. Estabelece as diretrizes e bases da educação nacional e dá outras providências. Brasília, DF, 1996.

CARONI, Regina A. L. Fracasso escolar e queixa do professor: uma relação a ser investigada. 3 I/0 I/20 I I. Dissertação (Mestrado em Educação - Universidade Nove de Julho, São Paulo, 20 I l .

COLLARES, Cecília A.; MOYSÉS, Maria Aparecida. Preconceito no cotidiano escolar: ensino e medicalização. São Paulo: Cortez, 1996.

CROCHIK, José L. Preconceito, indivíduo e cultura. São Paulo: Robe, 1997.

DIAS, Elaine T. D. M. A dúvida da continuidade dos estudos universitários: uma questão adolescente. Taubaté: Cabral, 1997.

DIAS, Elaine T. D. M. Subjetividade, docência e adolescência: impactos no ato educativo. In: ALMEIDA, Cleide; PERISSÉ, Gabriel (org.). Educação e linguagem: ensaios. São Paulo: USP; Porto: CEMOrOC, 2008. p. 59-66. (Notandum Libro II).

DIAS, Elaine T. D. M. Síndrome de burnout: a fragmentação dos saberes e o expurgo do sujeito. In: ALMEIDA, Cleide; PETRAGLIA, Izabel. Estudos de complexidade 4. São Paulo: Xamã, 20 I 0. p. 29-40.

DIAS, Elaine T. D. M. Profecias autorrealizadoras, subjetividade e pensamento complexo. In: DIAS, Elaine T. D. M.; PIRES, Maria de Fátima, P. C.; PAINI, Leonor D. Psicologia e Educação: uma interface entre saberes. Jundiaí: Paco, 2012.

MOCELIN, Valéria L. O sucesso escolar e o ensino de nove anos: um estudo exploratório. 30/0I/20 I 4 Dissertação (Mestrado em Educação - Universidade Nove de Julho, São Paulo, 2014.

MORIN, Edgar. A cabeça bem-feita: repensar a reforma, reformar o pensamento. Trad. Eloá Jacobina, 10. ed. Rio de Janeiro: Bretrand, 2004a.

MORIN, Edgar. O enigma do homem. Para uma nova antropologia. Trad. Fernando de Castro Ferro. Rio de Janeiro: Zahar, 1975.

MORIN, Edgar. Introdução ao pensamento complexo. Trad. Eliane Lisboa. Porto Alegre: Sulina, 2005a.

MORIN, Edgar. O método 4. As idéias, habitat, vida, costumes, organização. Trad. Juremir M. da Silva. 3 ed. Porto Alegre: Sulina, 2002.

MORIN, Edgar. O método 5: A Humanidade da humanidade - a identidade humana. Tradução de Juremir M. da Silva. 4 ed. Porto Alegre: Sulina, 2005b.

MORIN, Edgar. O método 6: ética. Trad. Juremir M. da Silva. 2ª ed. Porto Alegre: Sulina, 2005c.

MORIN, Edgar. Os sete saberes necessários à educação do futuro. Trad. Catarina. F. da Silva e Jeanne Sawaya. 9 ed. São Paulo: Cortez; Brasília, DF: Unesco, 2004b.

MOYSÉS, Maria Aparecida A.; COLLARES, Cecília A. L. Inteligência abstraída, crianças silenciadas: as avaliações de inteligência. Psicol. USP. São Paulo: EDUSP, v. 8, n. I, p. 63-89, 1997.

https://www.revistas.usp.br/psicousp/issue/view/8167 Acesso em: 12 out. 2010. 
PATTO, Maria Helena de S. Produção do fracasso escolar. São Paulo: Casa do Psicólogo, 1993.

PATTO, Maria Helena de S. Exercícios de indignação: escritos de educação e psicologia. São Paulo: Casa do Psicólogo, 2005.

SÃO PAULO. Secretaria da Educação do Estado de São Paulo. Educação especial: novas diretrizes. São Paulo, set, 2000.

SOUZA, Marilene M. P. R. Queixa escolar e atuação profissional: apontamentos pra formação do psicólogo. In: MEIRA, Maria Eugenia M. E. M.; ANTUNES, Mitsuko Aparecida M. A. Psicologia escolar: teorias críticas. São Paulo: Casa do Psicólogo, 2003.

TAKASE, Daniela G. A. Formação continuada de professores no âmbito da inclusão: diversidade e adversidades. 3 I/03/20 I I. Dissertação (Mestrado em Educação) -Universidade Nove de Julho, São Paulo, 201।.

\section{COMO CITAR ESSE ARTIGO}

DIAS, Elaine Teresinha Dal Mas. Alunos com necessidades educacionais especiais no ensino regular: obstáculos e limites. Debates em Educação, Maceió, v. 12, n. 28, p. 65I-664, Set./Dez. 2020. ISSN 2 175-6600. Disponível em: https://www.seer.ufal.br/index.php/debateseducacao/article/view/l0479. Acesso em: dd mmm. aaaa. 